\title{
Adenoviral Vectors in Veterinary Vaccine Development: Potential for Further Development
}

\author{
Olasumbo L. Ndi ${ }^{*}$, Mary D. Barton ${ }^{1}$, Thiru Vanniasinkam ${ }^{2}$ \\ ${ }^{1}$ Sansom Institute, School of Pharmacy and Medical Sciences, University of South Australia, Adelaide, Australia; ${ }^{2}$ School of Bio- \\ medical Sciences, Charles Sturt University, Wagga Wagga, Australia. \\ Email: "sumbo.ndi@unisa.edu.au
}

Received June $3^{\text {rd }}$, 2013; revised July $2^{\text {nd }}$, 2012; accepted July $15^{\text {th }}$, 2012

Copyright (C 2013 Olasumbo L. Ndi et al. This is an open access article distributed under the Creative Commons Attribution License, which permits unrestricted use, distribution, and reproduction in any medium, provided the original work is properly cited.

\begin{abstract}
Vaccines are an integral part of veterinary disease prevention. However there are still a significant number of veterinary diseases for which vaccines do not currently exist or where currently available vaccines do not provide adequate immunity. Adenoviruses have transitioned from tools for gene replacement therapy to bona fide vaccine delivery vehicles because of their ability to elicit potent cell-mediated and humoral responses making them ideal for use against viruses and other intracellular pathogens. Adenoviral vector based vaccines are likely to play a significant role in overcoming these problems in the future. However, this vector is under utilized in veterinary vaccine development at this time. This review focuses on adenoviral vector based vaccines developed to date and explores the potential for veterinary vaccine development based upon this platform: advantages and potential disadvantages of this technology are discussed as well as the potential for developing efficacious commercial veterinary adenoviral vector based vaccines.
\end{abstract}

Keywords: Veterinary Vaccines; Adenoviral Vector; Adenoviral Vector Vaccine; Vaccine Vector; Immune Response

\section{Viral Vectors in Vaccine Development}

The term "vaccine" which is from the Latin term "vacca," means cow was first coined by Edward Jenner, an English doctor in 1796 to describe the inoculation of humans with the cowpox virus to confer protection against the related human smallpox virus. The history of veterinary vaccine development starts with the well-known story of Louis Pasteur and his rabbit spinal cord vaccine and continues to this day with the demonstration of protection in animals by rabies virus reverse transcriptase DNA plasmid vaccination [1].

Depending on the animal groups under consideration, the criteria for successful animal or veterinary vaccines can be very different from those for human vaccines.

In most cases, the criteria for companion animal vaccines are similar to those for human vaccines because the health and welfare of the individual animal is of primary concern. The emphasis of livestock vaccines, on the other hand, is to improve overall animal production for the primary producers, since this will produce some cost benefits for the industry.

Vaccination against zoonotic or food-borne infections

*Corresponding author. is aimed at reducing or eliminating the risk for the consumer and in some cases to improve the productivity of the individual animal. Vaccination of wildlife is generally considered only with respect to infections that are transmittable to humans (zoonotic diseases), although welfare concerns are of increasing importance [2,3].

Live attenuated vaccines were the first form of vaccine and these have been successfully used for many years in economically important animal diseases as well as in companion animals [3,4]. A live attenuated virus vaccine is a live virus that has lost its virulence that is the ability to cause disease but still has the ability to induce protective immunity against the virulent virus. They are prepared either from a naturally occurring virus from another species (e.g. Jenner's cowpox) or are artificially attenuated. Although live attenuated vaccines are the most successful form of vaccine, they have been found to have some limitations or shortcoming. The reversion to virulence, differences in virulence in different hosts, preparation instability, heat lability are some of the risks associated with their use [3,5].

The recent advances in molecular biology and recombinant DNA technology have revolutionized the field of vaccine research with different cutting edge approaches 
being developed. This has helped in addressing some of the problems and concerns encountered in developing and using live attenuated vaccines. Today, both DNA and RNA viruses are extensively utilized in vaccine development. The use of viruses as vaccine vectors has a lot of advantages as well as disadvantages. Most viruses used in vector development such as adenoviruses and pox viruses have medium to fairly large genomes that are relatively easy to manipulate and are capable of infecting mammalian cells, making them ideal for use in veterinary and human vaccine development [6-9]. Some relatively small viruses such as Adeno-associated viruses have also been used in vaccine development [10].

\section{Adenoviruses as Vaccine Vectors}

Adenoviruses (AdV) are ubiquitous pathogens associated with most vertebrates such as reptiles, birds, mammals and amphibians [11-19]. They are non-enveloped, icosahedral viruses that replicate in the nucleus. They have a linear double stranded DNA of about 26 - $45 \mathrm{kbp}$. The viral capsid comprises 252 structural units (capsomers), including 240 Hexons (II) and 12 pentons (III). This capsid protects the viral genome ands plays a substantial role during virus entry into the host cell. They belong to the family Adenoviridae which is divided into 5 genera based on the host species and the DNA composition; Atadenovirus, Siadenovirus, Mastadenovirus, Aviadenovirus, Ichtadenovirus [12]. The human adenoviruses (HAdV) are classified within the genome Mastadenoviridae with 57 serotypes classified to date which are divided into seven sub groups (A-G).

Adenovirus vectors have become a very popular tool for gene transfer into mammalian cells [20-24]. The AdV genome is divided into early $(\mathrm{E})$ and late $(\mathrm{L})$ genes, expressed, respectively, before and after replication of the viral chromosome. E1 gene products are involved in the control of viral gene transcription, shutoff of cellular proteins and cellular transformation. The E2 gene codes for proteins involved in viral replication, including a DNA-binding protein involved in DNA elongation (E2A) and a DNA polymerase (E2B); E3 gene, dispensable for Ad replication, codes for proteins that interfere with the host immune response against virus infection; finally, the E4 genes are involved in the transition from early to late gene expression, the shutoff of host-cell gene expression, the viral replication and the assembly of the virion $[25,26]$.

Human AdV are by far the best characterised, and the vast majority of gene transfer studies involving Ad, whether for therapeutic or vaccine purposes, have been carried out with vectors derived from serotype 5 (HAdV-5) [7, 27-29]. Recently, other serotypes such as adenovirus serotype 26 have been developed as vaccine vectors [30].
Different strategies have been employed in the construction of AdV vectors. The vectors can be constructed to be replication competent or replication defective with most viral vectors available in both systems. In order to render these viruses replication defective one or more of the early genes that are required for virus multiplication (e.g. the E1 gene in adenovirus) are normally excised [31,32]. Generally, these replication defective adenoviral vectors are preferred for many reasons. They are usually considered to be safe, more so than replication competent viruses [33,34]. They are often more effective in prime boost protocols than replication competent vectors which have been shown to induce potent immune responses against both the viral vector antigens and the vaccine (transgene encoded) antigen with the resultant neutralizing antibodies against the vaccine vector severely reducing the efficacy of the vaccine when used as a boost [35]. Replication competent vectors may also cause lytic infections in the host cells, leading to apoptosis of infected cells and a reduction in the duration of antigen presentation, potentially compromising the efficacy of the vaccine [36]. Importantly, the use of replication defective adenoviral vectors, does not generally lead to the potentially serious consequences that have been associated with replication competent vectors, especially in immunocompromised hosts and those with relatively immature immune systems [37]. Conversely, it should be noted that some studies have shown that replication competent vectors can elicit stronger immune responses in the host than their replication defective counterparts [38]. Nevertheless, replication competent vectors present a major drawback; in that their use in permissive hosts gives rise to the production of infectious particles that can be released into the environment. This is not favourable in view of the legislation governing the use of genetically modified organisms.

An important advantage of adenoviral vector vaccines is that they lend themselves to delivery by various routes including in-vivo, intramuscular and oral. In addition, AdV vector based vaccines have been utilized successfully in prime boost protocols with other vaccine modalities $[39,40]$. The type of immune response generated by these vaccines can also be modulated using different doses and delivery methods, with mucosal delivery for example leading to more effective protection against certain pathogens by providing protection at the site of pathogen entry [41,42]. In addition, cell-mediated responses to a vaccine in particular may be markedly affected by the route of viral vector based vaccine delivery [41]. Advantageously, adenoviral vector vaccine technology lends itself to the development of multi-epitope vaccines including those that express multiple genes or fusion genes thereby leading to the development of vaccines that can elicit broad immune responses against 
multiple antigens from one or more pathogens [43].

One potential shortcoming of adenoviral vector vaccines, however, is that these vaccines may be ineffective and perhaps potentially harmful if used in the presence of pre-existing immunity to the vaccine vector as demonstrated in clinical studies on an HIV vaccine candidate; in this study vaccines with pre-existing immunity to the vaccine carrier were shown to be at greater risk of acquiring a fulminant HIV infection [44]. A number of other studies have also indicated that pre-existing antibodies to AdV affected the induction of humoral immune response following immunization resulting in lower immune response or reduced protection after challenge [45-47].

This problem may be circumvented however by the use adenoviral vector with lower sero prevalence in the target animal species. In the study by Geisbert et al. [8] HAd26 and HAd35 which segregate genetically from HAd5 and exhibit lower sero prevalence in humans, was used as vaccine vector. Their study showed that HAd26 and HAd35 vectors generate robust antigen-specific cellmediated and humoral immune responses against Ebola Virus glycoprotein and that HAd5 immune status does not affect the generation of GP-specific immune responses by the vaccines. Another way to circumvent this will be to design vaccine vectors using adenoviruses isolated from a different host species.

\section{Immune Responses Generated by Adenoviral Vectors}

Adenoviral vectors especially those first generation vectors that possess intact adenoviral genes have been shown to produce strong innate and adaptive responses in the host, these responses are made in response to viral gene products and the viral capsid. Not surprisingly the level of immune response is dose dependent. Depending on the number of viral genes deleted and especially with the gutless viral vectors that do not contain any adenoviral genes immune responses elicited by these vectors can be relatively weak. The potential for adenoviruses to elicit powerful $\mathrm{B}$ cell and $\mathrm{T}$ cell responses in the mammalian host are the main reason for the use of these vectors in vaccine development. The strong immune responses elicited by these vectors have been linked to their ability to infect immature dendritic cells thereby activating them to become mature antigen presenting dendritic cells thus promoting $\mathrm{T}$ cells responses $[48,49]$. Adenoviruses currently used in vaccine development or gene therapy are constructed as E1 or E3 gene deleted through to last generation vectors devoid of the entire adenoviral genome. Depending upon the genes deleted the immunogenicity of the vector can vary [48]. The effects of the gene deletions are taken into consideration in the creation of adenoviral vectors depending upon their use. In gene therapy for example, multiple genes are often deleted as gene therapy vectors unlike vaccine vectors should ideally not induce an immune response in the host. In vaccine development on the other hand potent immune responses that are specific for the vaccine antigen are required which requires long term expression of the vaccine antigen within the vaccinated host, this can be achieved by deleting the E1 gene and such vectors cannot cause apoptosis of the infected cells, therefore there is sustained presentation of the vaccine antigen.

Both innate and adaptive immune responses are induced by adenoviral vectors and responses are generated against the transgene but also the vector itself. Following systemic administration, adenoviral vectors will attach to the Coxsackie Adenovirus receptor (CAR) on host cells and are internalized. Initially entering the cell within an endosome the virus subsequently escapes from the endosome and from within the cytoplasm the viral DNA will enter the nucleus of the cell and is eventually transcribed [50]. Immune responses can be triggered by internalised viruses via various Toll-like receptors (TLR) [51]. The binding of the adenovirus fibre to the CAR receptor leads to the production of proteins such as P13K kinase and junctional adhesion molecule-like protein causing the production of various chemokines [52]. Significant levels of cytokines including IL-6 and TNF- $\alpha$ are usually detected within 24 hours following adenoviral vector administration. Importantly even when the vectors have few or no adenoviral genes they still elicit significant innate responses characterized by upregulated neutrophil and macrophage activity at the site of vector administration which are induced by the viral capsid [53]. These innate responses can also result in the elimination of significant numbers of viral vectors in a host [54]. Apart from their innate responses, significant humoral responses against the viral vector can result in the production of neutralizing antibodies against the vector. Overall, despite these issues adenoviral vectors are still considered to be amongst the best vectors for use in vaccine development.

\section{Adenoviral Vector Based Vaccines in Prime Boost Protocols}

Prime-boost vaccination using plasmid DNA and replication-defective adenovirus vectors has emerged as a highly effective strategy for vaccinating against various pathogens. Often this has involved constructing a DNA vaccine and a viral vector based vaccines both containing the same transgene. DNA vaccines have been aggressively researched since the early 90s and following extensive testing in clinical trials it is now known that these vaccines, whilst being largely ineffective as a sole vaccine, can be successfully used in prime boost immunizations. This approach has been investigated with superior 
results obtained using a DNA vaccine to prime the immune system followed by an adenoviral vector vaccine boost $[40,55,56]$. Generally, studies have shown that better antibody responses and strong cell-mediated immune responses, characterized by high levels of Th1 cytokines such as IFN gamma, antigen-specific CD4p and CD8p cells, are generated using the DNA prime/viral vector boost approach compared with using a single vaccine modality $[35,36]$. In some cases the efficacy of a prime boost vaccination protocol can be further enhanced with the administration of adjuvants such as glycosyl chitosan or CpG oligodeoxynucleotides $[57,58]$ and chicken CD154 [23]. Th1 cytokines such as IL-12 and IFN-gamma have also been used to enhance immune responses generated by prime boost vaccination protocols [59]. Successful use of an adenoviral vector vaccine in a prime boost regimen is exemplified in vaccination of cattle against bovine tuberculosis (TB). The current strategy on vaccine development for bovine TB is to improve on the existing vaccine, Bacille Calmette-Guerin (BCG). Studies conducted with BCG and a recombinant MVA or AdV vaccine expressing the 85A antigen in a prime boost approach demonstrate that this approach generates higher levels of cell-mediated immune responses than by using BCG alone [60,61]. Boosting with an adenovirus-vectored (Ad) tuberculosis vaccine AdAg $85 \mathrm{~A}$ through the intranasal mucosal route was able to enhance the long-term survival of BCG-primed guinea pigs following pulmonary Mycobacterium tuberculosis challenge [62]. Hammond et al. [55] demonstrated that a prime-boost vaccination strategy which comprised a naked DNA (pCI-gp55) prime followed by a boost with a live recombinant porcine adenovirus (rPAV-gp55) completely protected weaned pigs from disease following experimental challenge with classical swine fever virus. This strategy also protected against the transient febrile response observed in pigs vaccinated with rPAV-gp55 alone, and prevented any pathology in the animal. The results obtained by Sun et al. [63] demonstrate that the heterologous DNA prime and recombinant adenovirus boost strategy can indeed induce solid protective immunity against the classical swine fever virus (CSFV) in pigs. The results demonstrated that the pigs receiving pSFV1CS-E2/rAdV-E2 heterologous prime boost immunization developed significantly higher titres of CSFV-specific neutralizing antibodies and comparable $\mathrm{CD}^{+}$and $\mathrm{CD}^{+}$T-cell proliferation, compared to the pigs receiving double immunizations with rAdV-E2 alone. When challenged with virulent CSFV Shimen strain, the pigs of the heterologous prime boost group did not show clinical symptoms or viremia, which were observed in one of the 5 pigs immunized with rAdV-E2 alone and all the 5 control pigs immunized with an empty adenovirus.
Although the mechanism of action of prime boost vaccination protocols is not fully understood, it has been suggested that the process involves the ability of DNA vaccines to prime memory cells which are then able to respond fairly rapidly to the recombinant viral vector boost, resulting in heightened immune responses to the target antigen. If a recombinant virus was used to prime as well as boost, the effect may not be quite the same, as the immune responses generated by the prime would be primarily an inflammatory response that, when boosted with the same vector, would result in a rapid decline of the vaccine vector [64]. Some of these effects are brought about by the presence of vector specific antibodies formed during the priming response but there is evidence to suggest that $\mathrm{T}$ cell-mediated mechanisms may also play a significant role [65]. Some researchers, however, have reported success using multiple immunizations with viral vector based vaccines $[66,67]$ but this approach has not been adopted in veterinary vaccine development. Based upon published studies it is clear that the prime boost strategy is important to keep in mind when developing adenoviral vector based vaccines for veterinary pathogens.

\section{Adenoviral Vectors Currently Used in Veterinary Vaccines}

The appeal of AdV-based vaccine vectors stems from their use as efficacious vaccines [68]. Most studies to date have focused on human serotype AdVs, particularly human AdV type 5 (HAd5). Human serotype AdV vaccine vectors are particularly useful for development of veterinary vaccines as neutralizing antibodies to the vector will not usually be present in the vaccinates and to date a range of veterinary vaccine candidates have been developed using this platform [23,63,69]. Adenoviruses from various species have been developed as vectors and some examples are listed in Table $\mathbf{1 .}$

AdV vectors are acknowledged to be highly efficacious as vaccine carriers and are capable of inducing strong antibody, $\mathrm{CD}^{+}$and $\mathrm{CD}^{+} \mathrm{T}$ cell responses [70]. While some uses of viral vectors in cancer therapy rely on the production of a cytopathic effect within the host tissue [71] in the development of vaccines designed to protect the host against a range of pathogens such replication competent vectors are not required. Research to date shows that replication defective AdV vectors can induce higher $\mathrm{B}$ and $\mathrm{T}$ cell responses than other viral vectors (e.g. pox viral vectors), however, they may not induce significant $\mathrm{CD} 4^{+} \mathrm{T}$ cell responses as they do not establish a lytic infection in the host [72].

One of the major problems associated with vaccinating young animals is the presence of low levels of maternally derived antibodies; often insufficient to provide complete protection but enough to interfere with conventional vac- 
Table 1. Examples of adenoviruses that have been developed as veterinary vaccine vectors.

\begin{tabular}{|c|c|c|c|c|}
\hline Vector/ Transgene & Animal Model & Method of delivery; Dose & Results of animal studies & Reference \\
\hline $\begin{array}{l}\text { Canine adenovirus serotype } \\
\text { 2/rabies virus glycoprotein }\end{array}$ & Dogs & $\begin{array}{l}\text { Subcutaneous; } 10^{7.8} \text { TCID }_{50} \\
\text { (boost at } 14 \text { days) }\end{array}$ & $\begin{array}{l}100 \% \text { protection following challenge } \\
\text { with rabies virus }\end{array}$ & {$[78]$} \\
\hline $\begin{array}{l}\text { Human adenovirus serotype } \\
\text { 5/avian influenza virus haemag- } \\
\text { glutinin (HA) }\end{array}$ & Chickens & $\begin{array}{l}\text { Subcutaneous; } 1 \times 10^{7}, 1 \times 10^{8} \text {, } \\
5 \times 10^{8} \text { PFU (boost at } 5 \text { weeks) }\end{array}$ & $\begin{array}{l}\text { High levels of HA specific antibodies; } \\
\text { High levels of IFN-gamma }\end{array}$ & [23] \\
\hline $\begin{array}{l}\text { Bovine adenovirus serotype } \\
\text { 3/herpesvirus glycoprotein D } \\
\text { Porcine adenovirus serotype }\end{array}$ & Cattle & $\begin{array}{c}\text { Intratracheal; } 10^{8} \mathrm{PFU} \text { (boost at } \\
4 \text { and } 8 \text { weeks) }\end{array}$ & $\begin{array}{l}\text { Partial protection following challenge } \\
\text { with bovine herpesvirus }\end{array}$ & [79] \\
\hline $\begin{array}{l}\text { 3/transmissible gastroenteritis } \\
\text { virus spike gene }\end{array}$ & Pigs & Oral; $5 \times 10^{6} \mathrm{PFU}$ & High titres of virus neutralizing antibody & {$[80]$} \\
\hline $\begin{array}{l}\text { Ovine adenovirus//taenia ovis } \\
\text { 45W antigen }\end{array}$ & Sheep & & & [81] \\
\hline $\begin{array}{c}\text { Fowl adenovirus serotype } 1 \\
\text { (CELO)/VP2 protein of infec- } \\
\text { tious bursal disease virus } \\
\text { (IBDV) }\end{array}$ & Chickens & $\begin{array}{l}\text { Oro-nasal; } 3 \times 10^{8} \text { to } 8 \times 10^{8} \\
\text { PFU per animal (boost } 14 \text { days } \\
\text { after prime) }\end{array}$ & $\begin{array}{l}\text { Partial protection following lethal IBDV } \\
\text { challenge (complete protection was } \\
\text { achieved when vaccine was delivered } \\
\text { subcutaneously or intradermally) }\end{array}$ & [82] \\
\hline
\end{tabular}

cination. For instance, puppies are vulnerable to canine distemper virus (CDV) because conventional vaccines that are highly effective in older animals are not protective in these young animals due to the presence of low levels of antibodies acquired from the dams which have been immunized against CDV [73]. An important advantage of adenoviral vector based vaccines is that they can be used in neonates or young animals as they are not adversely affected by the presence of maternal antibodies [74]. This was clearly demonstrated in a study utilizing an E1-deleted replication defective AdH5 vector based swine influenza virus (SIV) vaccine. In this study, piglets born to dams previously exposed to SIV were immunized with a mixture of two AdH5 based vaccines expressing the hemagglutinin antigen or the nucleoprotein of SIV. Half of the vaccinated piglets were boosted 5 weeks later with commercial SIV H1N1 and H3N2 vaccine. A control group received a sham adenovirus prime at 1 week of age followed by the H1N1 and H3N2 boost at 5 weeks. Two weeks later all three groups of piglets were challenged with virulent H3N2; only piglets primed with the adenoviral vector based vaccines showed a significant increase in memory responses in the presence of maternally derived antibodies present against SIV H3N2 [75].

Adenoviral vectors have also been used in the construction of vaccines that can inhibit virus replication in the host. The principle of this technology is that the viral vector is engineered to express short hairpin RNAs (shRNA) which, when introduced into the host, will suppress the function of an important target protein expressed by the pathogenic virus. This approach has been used in the development of a replication defective AdH5 virus based vaccine [76] containing either the foot-andmouth disease virus (FMDV) structural protein 1D or polymerase 3D specific shRNA. When challenged with 100 ID $_{50}$ of homologous FMDV partial protection was observed in guinea pigs injected with a mixture of both vaccines $\left(2 \times 10^{9} \mathrm{pfu}\right)$ or the vaccine containing the FMDV polymerase 3D gene $\left(10^{6} \mathrm{pfu}\right)$ [76]. This method has not been widely utilised in vaccine development to date, however, the results of the Chen and co-workers' study suggest that this approach should be investigated further.

The route of vaccination has, in some cases, proved to be crucial to overcome interference from pre-existing neutralizing antibodies. In one study, the efficacy of a vaccination regimen using two replication competent canine adenovirus serotype 2 based CDV vaccines was investigated in pups that had maternally derived CDV and canine adenovirus specific antibodies. Pups vaccinated subcutaneously were protected while those vaccinated via the mucosa were not [73]. This suggests that in any study looking at the efficacy of viral vector vaccines multiple routes of administration should be evaluated.

One of the most important reasons to develop adenoviral vector based vaccines is that this platform would lend itself to the development of vaccines that can differentiate between infected and vaccinated animals (DIVA). For example, this approach has been used by Li et al. (2011) who developed a turkey herpesvirus vector based vaccine for avian influenza and Marek's disease [77]. This vaccine was designed so as not to elicit nucleoprotein specific antibody responses in the vaccinated host and could therefore be used in a DIVA protocol.

\section{The Potential for Commercial Adenoviral Vector Based Veterinary Vaccines}

Conventional vaccines have played an important role in the control and possible eradication of certain diseases e.g. rinderpest. However, new approaches to vaccine development are urgently required for those diseases where efficacious vaccines do not exist [83]. Currently however, veterinary vaccines comprise a fraction of the market size of human vaccines; consequently there are 
much lower levels of investment into veterinary vaccine research and development. These issues can have a negative impact on the utilization of new technologies in veterinary vaccine development.

The commercialization of vaccines whether for human or veterinary use usually begins following extensive testing of the vaccine candidate in animal models and field trials. The final stage of this arduous process would be market authorization which for a veterinary vaccine would involve obtaining permission from veterinary authorities to allow the vaccine to be made available to the relevant consumers [84]. Despite years of research into the technologically advanced DNA and viral/bacterial vector technologies, conventional vaccines based upon either killed or attenuated pathogens or recombinant antigens still form a major part of the veterinary vaccine market today. One of the main reasons for this is the relatively long process leading to commercialization of a new vaccine which involves establishing vaccine efficacy and safety prior to obtaining registration, which may be complicated if the vaccines were to be commercialized globally [85]. Furthermore, the need for global cooperation between governments and industry in veterinary vaccine development remains a pivotal issue in the future development of these vaccination agents; unlike human vaccine development for infections such as HIV and malaria, this arena has not yet been fully explored $[30,86]$. Over the years a number of adenoviral vector based veterinary vaccines have been developed but none are currently licensed. One such Adenoviral vector based veterinary vaccine is currently under consideration for commercialization. This is a replication-defective human adenovirus serotype 5 (Ad5) containing the capsid and 3C protease-coding regions of foot-and-mouth disease (FMD) virus as a vaccine candidate has been developed and gone through field trials and other testing in preparation for commercial production. Even though many of the trials have been successful; several US Department of Agriculture Centre for Veterinary Biologics regulatory requirements still need to be met in order to obtain product licensure $[87,88]$.

Most of the currently available viral vector based veterinary vaccines are based on other platforms such as Canary Pox virus, Fowl Pox virus and Baculovirus [89-92]. Adenoviral vector based systems are clearly underutilized in veterinary vaccine development despite being well characterized and shown to be potent inducers of protective immune responses [72]. If these vectors are to be used widely to construct veterinary vaccines that can be commercialized, more research needs to be undertaken on this platform, particularly studies focusing on the comparison of this platform with other viral vector platforms and the use of adenoviral vaccines in prime boost immunization protocols with non-adenoviral vector based vaccines.

\section{Conclusion and Challenges That Remain}

Adenoviral vector vaccines have been shown to induce potent immune responses in the host. It has been hypothesized that if pre-existing immunity to the vaccine vector is not present, these vaccines are likely to be highly effective against viral pathogens in particular that require robust cell-mediated immune responses in the host for protection. There is evidence to suggest however that even in the presence of neutralizing antibodies adenoviral vector based vaccine could work [93].

Despite the many advantages of this technology there are some potential drawbacks to consider, such as the potential toxicity of adenoviral vaccine vectors. For example, viral based vectors elicit an inflammatory cytokine response (by stimulating both innate and adaptive immune responses), thus promoting harmful side effects in the host [94]. In light of this, these viral vaccine vectors must be thoroughly evaluated for potentially harmful immunological reactions on the host immune system, especially in the context of pre-existing immunity to the vaccine vector prior to conducting field trials.

Other important issues to be considered when developing adenoviral vector based on vaccines are the choice of transgene and the stability of the vector genome. In order for a vaccine to be protective, the pathogen specific transgene used in the construction of the vaccine should contain highly immunogenic epitopes otherwise the immune responses generated by the vaccine will be suboptimal. Ideally extensive research to identify the most immunogenic antigens of a pathogen should therefore be undertaken before vaccine development begins. Studies conducted to ensure the stability of the viral vector genome must also be conducted soon after the vaccine is constructed and well before large scale production of the vaccine as it has been reported that mutants which do not express the vaccine transgene can randomly arise when producing large quantities of viral vector based vaccines [95]. Vaccines therefore need to be constructed using strategies that avoid cloning the transgene into sections of the viral vector that are relatively unstable and more prone to mutation or deletions.

There are still many important veterinary pathogens for which no vaccines currently exist. In addition, issues such as maintaining herd immunity and the potential waning of vaccine induced protection remain a serious challenge for eradication of important diseases such as foot-and-mouth disease using existing vaccines [83]. As human vaccine studies have shown the adenoviral vector platform has the potential to be used in the development of efficacious vaccines for veterinary pathogens where other approaches have failed, however, many challenges remain in regard to the development of these vaccines. 


\section{Acknowledgements}

We would like to thank the Australian Rural Industries Research and Development Corporation for providing research funding.

\section{REFERENCES}

[1] P. Carnieli, A. M. Ventura and E. L. Durigon, “Construction of a Recombinant Plasmid pSH-G Containing the Rabies-Virus Glycoprotein G Gene,” Journal of Venomous Animals and Toxins including Tropical Diseases, Vol. 13, No. 4, 2007, pp. 874-880. doi:10.1590/S1678-91992007000400015

[2] M. Lombard, P. P. Pastoret and A. M. Moulin, “A Brief History of Vaccines and Vaccination," Revue et Scientifique Technique (International Office of Epizootics), Vol. 26, No. 1, 2007, pp. 29-48.

[3] E. N. T. Meeusen, J. Walker, A. Peters, P. Pastoret and G. Jungersen, "Current Status of Veterinary Vaccines," Clinical Microbiology Reviews, Vol. 20, No. 3, 2007, pp. 489-510. doi:10.1128/CMR.00005-07

[4] D. J. Alexander, "Newcastle Disease,” In: H. G. Purchase, L. H. Arp, C. H. Domermuth and J. E. Pearson, Eds., $A$ Laboratory Manual for the Isolation and Identification of Avian Pathogens, American Association for Avian Pathologists, Inc., Philadelphia, 1989, pp. 114-120.

[5] A. Brun, E. Albina, T. Barret, D. A. G. Chapman, M. Czub, L. K. Dixon, G. M. Keil, B. Klonjkowski, M.-F. Le Potier, G. V. Libeau, J. Ortego, J. Richardson and H. H. Takamatsu, “Antigen Delivery Systems for Veterinary Vaccine Development: Viral-Vector Based Delivery Systems," Vaccine, Vol. 26, No. 51, 2008, pp. 6508-6528. doi:10.1016/j.vaccine.2008.09.044

[6] M. M. Erdmana, K. I. Kamrud, D. L. Harris and J. Smith, “Alphavirus Replicon Particle Vaccines Developed for Use in Humans Induce High Levels of Antibodies to Influenza Virus Hemagglutinin in Swine: Proof of Concept,” Vaccine, Vol. 28, No. 3, 2010, pp. 594-596. doi:10.1016/j.vaccine.2009.10.015

[7] E. S. Gabitzsch, Y. Xu, L. H. Yoshida, J. Balint, A. Amalfitano and F. R. Jones, "Novel Adenovirus Type 5 Vaccine Platform Induces Cellular Immunity against HIV-1 Gag, Pol, Nef Despite the Presence of Ad5 Immunity,” Vaccine, Vol. 27, No. 46, 2009, pp. 6394-6398. doi:10.1016/j.vaccine.2009.06.028

[8] T. W. Geisbert, M. Bailey, L. Hensley, C. Asiedu, J. Geisbert, D. Stanley, A. Honko, J. Johnson, S. Mulangu, M. G. Pau, J. Custers, J. Vellinga, J. Hendriks, P. Jahrling, M. Roederer, J. Goudsmit, R. Koup and N. J. Sullivan, "Recombinant Adenovirus Serotype 26 (Ad26) and Ad35 Vaccine Vectors Bypass Immunity to Ad5 and Protect Nonhuman Primates against Ebolavirus Challenge," Journal of Virology, Vol. 85, No. 9, 2011, pp. 4222-4233. doi:10.1128/JVI.02407-10

[9] M. C. Pardo, J. E. Bauman and M. Mackowiak, "Protection of Dogs against Canine Distemper by Vaccination with a Canarypox Virus Recombinant Expressing Canine Distemper Virus Fusion and Hemoglutinin Glycopro- teins," American Journal of Veterinary Research, Vol. 58, No. 8, 1997, pp. 833-836.

[10] D. Kuck, T. Lau, B. Leuchs, A. Kern, M. Müller, L. Gissmann and J. A. Kleinschmidt, "Intranasal Vaccination with Recombinant Adeno-Associated Virus Type 5 against Human Papillomavirus Type 16 L1,” Journal of Virology, Vol. 80, No. 6, 2006, pp. 2621-2630. doi:10.1128/JVI.80.6.2621-2630.2006

[11] M. Benko, P. Élo, K. Ursu, W. Ahne, S. E. LaPatra, D. Thomson and B. Harrach, "First Molecular Evidence for the Existence of Distinct Fish and Snake Adenoviruses," Journal of Virology, Vol. 76, No. 19, 2002, pp. 1005610059. doi:10.1128/JVI.76.19.10056-10059.2002

[12] A. J. Davison, M. Benko and B. Harrach, "Genetic Content and Evolution of Adenoviruses,” Journal of General Virology, Vol. 84, No. 11, 2003, pp. 2895-2908. doi:10.1099/vir.0.19497-0

[13] J. Dean, K. S. Latimer, J. L. Oaks, M. Schrenzel, P. T. Redig and A. Wunschman, "Falcon Adenovirus Infection in Breeding Taita Falcons (Falco fasciinucha)," Journal of Veterinary Diagnostic Investigation, Vol. 18, No. 3, 2006, pp. 282-286. doi:10.1177/104063870601800310

[14] K. Erles, E. J. Dubovi, H. W. Brooks and J. Brownlie, "Longitudinal Study of Viruses Associated with Canine Infectious Respiratory Disease,” Journal of Clinical Microbiology, Vol. 42, No. 10, 2004, pp. 4524-4529. doi:10.1128/JCM.42.10.4524-4529.2004

[15] R. P. Hedrick, J. Speas, M. L. Kent and T. McDowell, "Adenovirus Like Particles Associated with a Disease of Cultured White Sturgeon Acipenser transmontanus," Canadian Journal of Fish and Aquatic Science, Vol. 42, No. 7, 1985, pp. 1231-1235. doi:10.1139/f85-165

[16] E. R. Kovacs, J. Mate, D. Adam, H. Balazs and M. Benko, "Recognition and Partial Genome Characterization by Non-Specific DNA Amplification and PCR of a New Siadenovirus Species in a Sample Originating from Parus major, a Great Tit,” Journal of Virological Methods, Vol. 163, No. 2, 2010, pp. 262-268. doi:10.1016/j.jviromet.2009.10.007

[17] T. H. Lim, B. Y. Kim, M. S. Kim, J. H. Jang, D. H. Lee, Y. K. Kwon, J. B Lee, S. Y. Park, I. S. Choi and C. S. Song, "Outbreak of Gizzard Erosion Associated with Fowl Adenovirus Infection in Korea,” Poultry Science, Vol. 91, No. 5, 2012, pp. 1113-1117. doi:10.3382/ps.2011-02050

[18] H. D. Lehmkuhl and R. C. Cutlip, “A New Goat Adenovirus Isolate Proposed as the Prototype Strain for Goat Adenovirus Serotype 1,” Archives of Virology, Vol. 144, No. 8, 1999, pp. 1611-1618. doi:10.1007/s007050050614

[19] J. Smyth and M. McNulty, “Adenoviridae,” In: M. Pattison, P. McMullin, J. Bradbury and D. Alexander, Eds., Poultry Diseases, Elsevier, New York, 2008, pp. 367-381. doi:10.1016/B978-0-7020-2862-5.50036-2

[20] P. Ketzer, S. F. Haas, S. Engelhardt, J. S. Hartig and D. M. Nettelbeck, "Synthetic Riboswitches for External Regulation of Genes Transferred by Replication-Deficient and Oncolytic Adenoviruses," Nucleic Acids Research, Vol. 40, No. 21, 2012, p. e167. doi:10.1093/nar/gks734

[21] B. Klonjkowski, D. Klein, S. Galea, F. Gavard, M. Mon- 
teil, L. Duarte, A. Fournier, S. Sayon, K. Gorrna, R. Ertl, N. Cordonnier, P. Sonigo, M. Eloit and J. Richardson, "Gag-Specific Immune Enhancement of Lentiviral Infection after Vaccination with an Adenoviral Vector in an Animal Model of AIDS,” Vaccine, Vol. 27, No. 6, 2009, pp. 928-939. doi:10.1016/j.vaccine.2008.11.086

[22] H. Murakami, R. Q. Miao, L. Chao and J. Chao, “Adenovirus-Mediated Kallikrein Gene Transfer Inhibits Neointima Formation via Increased Production of Nitric Oxide in Rat Artery,” Immunopharmacology, Vol. 44, No. 1-2, 1999, pp. 137-143. doi:10.1016/S0162-3109(99)00120-4

[23] O. S. Ramos, A. G. Pose, S. Gomez-Puerta, J. N. Gomez, A. V. Redondo, J. C. A. Benites, L. S. Amaran, N. C. Parra and J. R. T.Alonso, "Avian CD154 Enhances Humoral and Cellular Immune Responses Induced by an Adenovirus Vector-Based Vaccine in Chickens," Comparative Immunology, Microbiology and Infectious Diseases, Vol. 34, No. 3, 2011, pp. 259-265. doi:10.1016/j.cimid.2010.12.001

[24] B. Trapnell and M. Gorziglia, "Gene Therapy Using Adenoviral Vectors," Current Opinion in Biotechnology, Vol. 5, No. 6, 1994, pp. 617-625. doi:10.1016/0958-1669(94)90084-1

[25] J. L. Imler, "Adenovirus Vectors as Recombinant Viral Vaccines,” Vaccine, Vol. 13, No. 13, 1995, pp. 11431151. doi:10.1016/0264-410X(95)00032-V

[26] W. Russell, "Update on Adenovirus and Its Vectors," Journal of General Virology, Vol. 81, No. 11, 2000, pp. 2573-2604.

[27] R. R. Bradley, D. M. Lynch, M. J. Iampietro, E. N. Borducchi and D. H. Barouch, "Adenovirus Serotype 5 Neutralizing Antibodies Target Both Hexon and Fiber Following Vaccination and Natural Infection," Journal of Virology, Vol. 86, No. 1, 2012, pp. 625-629. doi:10.1128/JVI.06254-11

[28] M. K. Knowles, D. Roberts, S. Craig, M. Sheen, S. A. Nadin-Davis and A. I. Wandeler, "In Vitro and In Vivo Genetic Stability Studies of a Human Adenovirus Type 5 Recombinant Rabies Glycoprotein Vaccine (ONRAB)," Vaccine, Vol. 27, No. 20, 2009, pp. 2662-2668. doi:10.1016/j.vaccine.2009.02.074

[29] M. Suleman, S. Galea, F. Gavard, N. Merillon, B. Klonjkowski, E. Tartour and J. Richardson, “Antigen Encoded by Vaccine Vectors Derived from Human Adenovirus Serotype 5 Is Preferentially Presented to $\mathrm{CD}^{+} \mathrm{T}$ Lymphocytes by the $\mathrm{CD}^{+}$Dendritic Cell Subset," Vaccine, Vol. 29, No. 35, 2011, pp. 5892-5903. doi:10.1016/j.vaccine.2011.06.071

[30] J. Esparza, “The Global HIV Vaccine Enterprise,” International Microbiology, Vol. 8, No. 2, 2005, pp. 93-101.

[31] A. Lieber, C. Y. He, I. IKirillova and M. A. Kay, "Recombinant Adenoviruses with Large Deletions Generated by Cre-Mediated Excision Exhibit Different Biological Properties Compared with First-Generation Vectors in Vitro and in Vivo," Journal of Virology, Vol. 70, No. 12, 1996, pp. 8944-8960.

[32] J. Schaack, “Adenovirus Vectors Deleted for Genes Essential for Viral DNA Replication," Frontiers in Bioscience, Vol. 10, 2005, pp. 1146-1155. doi: $10.2741 / 1607$

[33] W. Oualikene, P. Gonin and M. Eloit, "Short and Long Term Dissemination of Deletion Mutants of Adenovirus in Permissive (Cotton Rat) and Non-Permissive (Mouse) Species,” Journal of General Virology, Vol. 75, No. 10, 1994, pp. 2765-2768. doi:10.1099/0022-1317-75-10-2765

[34] L. Peiperl, C. Morgan, Z. Moodie, H. Li, N. Russell, B. S. Graham, G. D. Tomaras, S. C. De Rosa, M. J. McElrath and NIAID Vaccines Trials Network, "Safety and Immunogenicity of a Replication-Defective Adenovirus Type 5 HIV Vaccine in Ad5-Seronegative Persons: A Randomized Clinical Trial (HVTN 054),” PLoS ONE, Vol. 5, No. 10, 2010, p. e13579.

doi:10.1371/journal.pone.0013579

[35] L. Wu, W. Kong and G. Nabel, "Enhanced Breadth of CD4 T-Cell Immunity by DNA Prime and Adenovirus Boost Immunization to Human Immunodeficiency Virus Env and Gag Immunogens,” Journal Virology, Vol. 79, No. 13, 2005, pp. 8024-8031. doi:10.1128/JVI.79.13.8024-8031.2005

[36] T. Vanniasinkam and H. C. J. Ertl, “Adenoviral Gene Delivery for HIV-1 Vaccination,” Current Gene Therapy, Vol. 5, No. 2, 2005, pp. 203-212. doi:10.2174/1566523053544236

[37] T. Kojaoghlanian, P. Flomenberg and M. S. Horwitz, "The Impact of Adenovirus Infection on the Immunocompromised Host,” Review of Medical Virology, Vol. 13, No. 3, 2003, pp. 155-171. doi:10.1002/rmv.386

[38] Y. Zhu, P. Rota, L. Wyatt, A. Tamin, S. Rozenblatt, N. Lerche, B. Moss, W. Bellini and M. McChesney, "Evaluation of Recombinant Vaccinia Virus: Measles Vaccines in Infant Rhesus Macaques with Preexisting Measles Antibody," Virology, Vol. 276, No. 1, 2000, pp. 202-213. doi:10.1006/viro.2000.0564

[39] T. Vanniasinkam, S. T. Reddy and H. C. Ertl, "DNA Immunization Using a Non-Viral Promoter," Virology, Vol. 344, No. 2, 2006, pp. 412-420. doi:10.1016/j.virol.2005.08.040

[40] H. P. Zhao, J. F. Sun, N. Li, Y. Sun, Y. Wang and H. J. Qiu, "Prime-Boost Immunization Using Alphavirus Replicon and Adenovirus Vectored Vaccines Induces Enhanced Immune Responses against Classical Swine Fever Virus in Mice," Veterinary Immunology Immunopathology, Vol. 131, No. 3-4, 2009, pp. 158-166. doi:10.1016/j.vetimm.2009.04.003

[41] P. Holst, C. Ørskov, A. R. Thomsen and J. P. Christensen, "Quality of the Transgene-Specific CD8+ T Cell Response Induced by Adenoviral Vector Immunization Is Critically Influenced by Virus Dose and Route of Vaccination,” Journal of Immunology, Vol. 184, No. 8, 2010, pp. 4431-4439. doi:10.4049/jimmunol.0900537

[42] A. Patel, Y. Zhang, M. Croyle, K. Tran, M. Gray, J. Strong, H. Feldmann, J. M. Wilson and G. P. Kobinger, "Mucosal Delivery of Adenovirus-Based Vaccine Protects against Ebola Virus Infection in Mice,” Journal of Infectious Diseases, Vol. 196, Suppl. 2, 2007, pp. 413420. doi:10.1086/520603

[43] T. J. Bull, S. C. Gilbert, S. Sridhar, R. Linedale, N. Dierkes, K. Sidi-Boumedine and J. Hermon-Taylor, “A 
Novel Multi-Antigen Virally Vectored Vaccine against Mycobacterium avium subspecies paratuberculosis," PLoS ONE, Vol. 2, No. 11, 2007, p. e1229. doi:10.1371/journal.pone.0001229

[44] R. P. Sekaly, "The Failed HIV Merck Vaccine Study: A Step Back or a Launching Point for Future Vaccine Development," Journal of Experimental Medicine, Vol. 205, No. 1, 2008, pp. 7-12. doi:10.1084/jem.20072681

[45] K. McCoy, N. Tatsis, B. Korioth-Schmitz, M. O. Lasaro, S. E. Hensley, S. Lin, Y. Li, W. Giles-Davis, A. Cun, D. Zhou, Z. Xiang, N. L. Letvin and H. C. J. Ertl, "Effect of Preexisting Immunity to Adenovirus Human Serotype 5 Antigens on the Immune Responses of Nonhuman Primates to Vaccine Regimens Based on Human- or Chimpanzee-Derived Adenovirus Vectors," Journal of Virology, Vol. 81, No. 12, 2007, pp. 6594-6604. doi:10.1128/JVI.02497-06

[46] A. Pandey, N. Singh, S. V. Vemula, L. Couetil, J. M. Katz, R. Donis, S. Sambhara and S. K. Mittal, "Impact of Preexisting Adenovirus Vector Immunity on Immunogenicity and Protection Conferred with an AdenovirusBased H5N1 Influenza Vaccine,” PLoS ONE, Vol. 7, No. 3, 2012, p. e33428. doi:10.1371/journal.pone.0033428

[47] J. S. Richardson, M. C. Abou, K. N. Tran, A. Kumar, B. M. Sahai and G. P. Kobinger, "Impact of Systemic or Mucosal Immunity to Adenovirus on Ad-Based Ebola Virus Vaccine Efficacy in Guinea Pigs,” Journal of Infectious Diseases, Vol. 204, Suppl. 3, 2011, pp. S1032S1042. doi:10.1093/infdis/jir332

[48] J. F. Engelhardt, L. Litzky and J. M. Wilson, "Prolonged Transgene Expression in Cotton Rat Lung with Recombinant Adenoviruses Defective in E2a," Human Gene Therapy, Vol. 5, No. 10, 1994, pp. 1217-1229. doi:10.1089/hum.1994.5.10-1217

[49] A. E. Morelli, A. T. Larregina, R. W. Ganster, A. F. Zahorchak, J. M. Plowey, T. Takayama, A. J. Logar, P. D. Robbins, L. D. Falo and A. W. Thomson, "Recombinant Adenovirus Induces Maturation of Dendritic Cells via an NF-Kappab-Dependent Pathway," Journal of Virology, Vol. 74, No. 20, 2000, pp. 9617-9628.

[50] L. Trotman, N. Mosberger, M. Fornerod, R. Stidwill and U. Greber, "Import of Adenovirus DNA Involves the Nuclear Pore Complex Receptor CAN/Nup214 and Histone H1,” Nature Cell Biology, Vol. 3, No. 12 2001, pp. 10921100. doi:10.1038/ncb1201-1092

[51] S. Uematsu and S. Akira, "Toll-Like Receptors and Type I Interferons,” Journal of Biological Chemistry, Vol. 282, No. 21, 2007, pp. 15319-15323. doi:10.1074/jbc.R700009200

[52] P. Verdino, D. A. Witherden, W. L. Havran and I. A. Wilson, "The Molecular Interaction of CAR and JAML Recruits the Central Cell Signal Transducer PI3K,” Science, Vol. 329, No. 5996, 2010, pp. 1210-1214. doi:10.1126/science.1187996

[53] N. Bessis, F. GarciaCozar, M. C. Boissier, "Immune Responses to Gene Therapy Vectors: Influence on Vector Function and Effector Mechanisms," Gene Therapy, Vol. 11, Suppl. 1, 2004, pp. S10-S17. doi:10.1038/sj.gt.3302364
[54] S. Worgall, G. Wolff, E. Falck-Pedersen and R. Crystal, "Innate Immune Mechanisms Dominate Elimination of Adenoviral Vectors Following in Vivo Administration," Human Gene Therapy, Vol. 8, No. 1, 1997, pp. 37-44. doi:10.1089/hum.1997.8.1-37

[55] J. M. Hammond, E. S. Jansen, C. J. Morrissy, W. V. Goff, G. C. Meehan, M. M. Williamson, C. Lenghaus, K. W. Sproat, M. E. Andrew, B. E. H. Coupar and M. A. Johnson, "A Prime-Boost Vaccination Strategy Using Naked DNA Followed by Recombinant Porcine Adenovirus Protects Pigs from Classical Swine Fever," Veterinary Microbiology, Vol. 80, No. 2, 2001, pp. 101-119. doi:10.1016/S0378-1135(00)00388-6

[56] S. J. Kim, H. K. Kim, Y. W. Han, A. G. Aleyas, J. A. George, H. A. Yoon, D. J. Yoo, K. Kim and S. K. Eo, "Multiple Alternating Immunizations with DNA Vaccine and Replication Incompetent Adenovirus Expressing gB of Pseudorabies Virus Protect Animals against Lethal Virus Challenge," Journal of Microbiology and Biotechnology, Vol. 18, No. 7, 2008, pp. 1326-1334.

[57] S. Gogev, K. de Fays, M. F. Versali, S. Gautier and E. Thiry, "Glycol Chitosan Improves the Efficacy of Intranasally Administrated Replication Defective Human Adenovirus Type 5 Expressing Glycoprotein D of Bovine Herpesvirus," Vaccine, Vol. 22, No. 15-16, 2004, pp. 1946-1953. doi:10.1016/j.vaccine.2003.11.011

[58] S. D. Perkins, A. J. Williams, L. M. O’Brien, T. R. Laws and R. J. Phillpotts, "CpG Used as an Adjuvant for an Adenovirus-Based Venezuelan Equine Encephalitis Virus Vaccine Increases the Immune Response to the Vector, but not to the Transgene Product," Viral Immunology, Vol. 21, No. 4, 2008, pp. 451-457. doi:10.1089/vim.2008.0052

[59] L. Bracci, I. Canini, M. Venditti, M. Spada, S. Puzelli, I. Donatelli, F. Belardelli and E. Proietti, "Type I IFN as a Vaccine Adjuvant for Both Systemic and Mucosal Vaccination against Influenza Virus,” Vaccine, Vol. 24, Suppl. 2, 2006, pp. 56-57. doi:10.1016/j.vaccine.2005.01.121

[60] H. M. Vordermeier, M. A. Chambers, B. M. Buddle, J. M. Pollock and R. G. Hewinson, "Progress in the Development of Vaccines and Diagnostic Reagents to Control Tuberculosis in Cattle,” The Veterinary Journal, Vol. 171, No. 2, 2006, pp. 229-244.

[61] H. M. Vordermeier, B. Villarreal-Ramos, P. J. Cockle, M. McAulay, S. G. Rhodes, T. Thacker, S. C. Gilbert, H. McShane, A. V. Hill, Z. Xing and R. G. Hewinson, "Viral Booster Vaccines Improve Mycobacterium Bovis BCGInduced Protection against Bovine Tuberculosis," Infection and Immunity, Vol. 77, No. 8, 2009, pp. 3364-3373.

[62] Z. Xing, C. T. McFarland, J. M. Sallenave, A. Izzo, J. Wang and D. N. McMurray, "Intranasal Mucosal Boosting with an Adenovirus-Vectored Vaccine Markedly Enhances the Protection of BCG-Primed Guinea Pigs against Pulmonary Tuberculosis,” PLoS ONE, Vol. 4, No. 6, 2009, p. e5856. doi:10.1371/journal.pone.0005856

[63] Y. Sun, N. Li, H. Y. Li, M. Li and H. J. Qiu, "Enhanced Immunity against Classical Swine Fever in Pigs Induced by Prime-Boost Immunization Using an Alphavirus Replicon-Vectored DNA Vaccine and a Recombinant Ade- 
novirus," Veterinary Immunology and Immunopathology, Vol. 137, No. 1-2, 2010, pp. 20-27. doi:10.1016/j.vetimm.2010.04.005

[64] J. Schneider, S. C. Gilbert, C. M. Hannan, P. Dégano, E. Prieur, E. G. Sheu, M. Plebanski and A. V. Hill, "Induction of $\mathrm{CD}^{+} \mathrm{T}$ Cells Using Heterologous Prime-Boost Immunisation Strategies,” Immunological Reviews, Vol. 170 , No. 1, 1999, pp. 29-38. doi:10.1111/j.1600-065X.1999.tb01326.x

[65] A. de Mare, A. J. Lambeck, J. Regts, G. M.van Dam, H. W. Nijman, H. Snippe, J. Wilschut and T. Daemen, "Viral Vector-Based Prime-Boost Immunization Regimens: A Possible Involvement of T-Cell Competition," Gene Therapy, Vol. 15, No. 6, 2008, pp. 393-403. doi:10.1038/sj.gt.3303060

[66] B. Asefa, N. Korokhov and F. Lemiale, "Heterologous HIV-Based Lentiviral/Adenoviral Vectors Immunizations Result in Enhanced HIV-Specific Immunity," Vaccine, Vol. 28, No. 20, 2010, pp. 3617-3624. doi:10.1016/j.vaccine.2009.12.047

[67] E. K. Roediger, K. Kugathasan, X. Zhang, B. D. Lichty and Z. Xing, "Heterologous Boosting of Recombinant Adenoviral Prime Immunization with a Novel Vesicular Stomatitis Virus-Vectored Tuberculosis Vaccine," Molecular Therapy, Vol. 16, No. 6, 2008, pp. 1161-1169. doi:10.1038/mt.2008.59

[68] F. H. J. Top, B. A. Dudding, P. K. Russel and E. L. Buescher, "Control of Respiratory Disease in Recruits with Types 4 and 7 Adenovirus Vaccines," American Journal of Epidemiology, Vol. 94, No. 2, 1971, pp. 142146.

[69] B. Zeshan, L. Zhang, J. Bai, X. Wang, J. Xu and P. Jiang, "Immunogenicity and Protective Efficacy of a Replication-Defective Infectious Bronchitis Virus Vaccine Using an Adenovirus Vector and Administered in ovo," Journal of Virology Methods, Vol. 166, No. 1-2, 2010, pp. 54-59. doi:10.1016/j.jviromet.2010.02.019

[70] B. Barefoot, N. J. Thornburg, D. H. Barouch, J. S. Yu, C. Sample, R. E. Johnston, H. X. Liao, T. B. Kepler, B. F. Haynes and E. Ramsburg, "Comparison of Multiple Vaccine Vectors in a Single Heterologous Prime-Boost Trial,” Vaccine, Vol. 26, No. 48, 2008, pp. 6108-6118. doi:10.1016/j.vaccine.2008.09.007

[71] R. C. Carlisle, S. S. Briggs, A. B. Hale, N. K. Green, K. D. Fisher, T. Etrych, K. Ulbrich, V. Mautner and L. W. Seymour, "Use of Synthetic Vectors for Neutralizing Antibody Resistant Delivery of Replicating Adenovirus DNA,” Gene Therapy, Vol. 13, No. 22, 2006, pp. 15791586. doi:10.1038/sj.gt.3302814

[72] J. Millar, D. Dissanayake, T. C. Yang, N. Grinshtein, C. Evelegh, Y. Wan and J. Bramson, "The Magnitude of the $\mathrm{CD}^{+} \mathrm{T}$ Cell Response Produced by Recombinant Virus Vectors Is a Function of Both the Antigen and the Vector," Cellular Immunology, Vol. 250, No. 1-2, 2007, pp. 55-67. doi:10.1016/j.cellimm.2008.01.005

[73] L. Fischer, J. P. Tronel, C. Pardo-David, P. Tanner, G. Colombet, J. Minke and J. C. Audonnet, "Vaccination of Puppies Born to Immune Dams with a Canine Adenovirus-Based Vaccine Protects against a Canine Distemper
Virus Challenge," Vaccine, Vol. 20, No. 29-30, 2002, pp. 3485-3497. doi:10.1016/S0264-410X(02)00344-4

[74] Z. Q. Xiang, G. P. Gao, A. Reyes-Sandoval, Y. Li, J. M. Wilson and H. C. Ertl, "Oral Vaccination of Mice with Adenoviral Vectors Is not Impaired by Preexisting Immunity to the Vaccine Carrier," Journal of Virology, Vol. 77, No. 20, 2003, pp. 10780-10789. doi:10.1128/JVI.77.20.10780-10789.2003

[75] R. D. Wesley and K. M. Lager, “Overcoming Maternal Antibody Interference by Vaccination with Human Adenovirus 5 Recombinant Viruses Expressing the Hemagglutinin and the Nucleoprotein of Swine Influenza Virus," Veterinary Microbiology, Vol. 118, No. 1-2, 2006, pp. 67-75. doi:10.1016/j.vetmic.2006.07.014

[76] W. Chen, M. Liu, Y. Jiao, W. Yan, X. Wei, J. Chen, L. Fei, Y. Liu, X. Zuo, F. Yang, Y. Lu and Z. Zheng, “Adenovirus-Mediated RNA Interference against Foot-andMouth Disease Virus Infection Both in Vitro and in Vivo," Journal of Virology, Vol. 80, No. 7, 2006, pp. 3559-3566. doi:10.1128/JVI.80.7.3559-3566.2006

[77] Y. Li, K. Reddy, S. M. Reid, W. J. Cox, I. H. Brown, P. Britton, V. Nair and M. Iqbal, "Recombinant Herpesvirus of Turkeys as a Vector-Based Vaccine against Highly Pathogenic H7N1 Avian Influenza and Marek's Disease," Vaccine, Vol. 29, No. 46, 2011, pp. 8257-8266. doi:10.1016/j.vaccine.2011.08.115

[78] R. Hu, S. Zhang, A. R. Fooks, H. Yuan, Y. Liu, H. Li, C. Tu, X. Xia and Y. Xiao, "Prevention of Rabies Virus Infection in Dogs by a Recombinant Canine Adenovirus Type-2 Encoding the Rabies Virus Glycoprotein," $M i$ crobes and Infection, Vol. 8, No. 4, 2006, pp. 1090-1097. doi:10.1016/j.micinf.2005.11.007

[79] P. Reddy, N. Idamakanti, C. Pyne, A. Zakhartchouk, D. L. Godson, Z. Papp, M. E. Baca-Estrada, L. A. Babiuk, G. K. Mutwiri and S. K. Tikoo, "The Immunogenicity and Efficacy of Replication-Defective and Replication-Competent Bovine Adenovirus-3 Expressing Bovine Herpesvirus-1 Glycoprotein gD in Cattle,” Veterinary Immunology and Immunopathology, Vol. 76, No. 3-4, 2000, pp. $257-$ 268. doi:10.1016/S0165-2427(00)00217-8

[80] T. Tuboly and E. Nagy, "Construction and Characterization of Recombinant Porcine Adenovirus Serotype 5 Expressing the Transmissible Gastroenteritis Virus Spike Gene,” Journal of General Virology, Vol. 82, No. 1, 2001, pp. 183-190.

[81] J. S. Rothel, D. B. Boyle, G. W. Both, A. D. Pye, J. G. Waterkeyn, P. R. Wood and M. W. Lightowlers, "Sequential Nucleic Acid and Recombinant Adenovirus Vaccination Induces Host-Protective Immune Responses against Taenia Ovis Infection in Sheep,” Parasite Immunology,Vol. 19, No. 5, 1997, pp. 221-227. doi:10.1046/j.1365-3024.1997.d01-200.x

[82] A. Francois, C. Chevalier, B. Delmas, N. Eterradossi, D. Toquin, G. Rivallan and P. Langlois, “Avian Adenovirus CELO Recombinants Expressing VP2 of Infectious Bursal Disease Virus Induce Protection against Bursal Disease in Chickens," Vaccine, Vol. 22, No. 17-18, 2004, pp. 2351-2360. doi:10.1016/j.vaccine.2003.10.039

[83] J. Domenech, J. Lubroth and K. Sumption, "Immune 
Protection in Animals: The Examples of Rinderpest and Foot-and-Mouth Disease," Journal of Comparative Pathology, Vol. 142, Suppl. 1, 2010, pp. S120-S124. doi:10.1016/j.jcpa.2009.11.003

[84] J. G. Heldens, J. R. Patel, N. Chanter, G. J. Ten Thij, M. Gravendijck, V. E. Schijns, A. Langen and T. P. Schetters, "Veterinary Vaccine Development from an Industrial Perspective," The Veterinary Journal, Vol. 178, No. 1, 2008, pp. 7-20. doi:10.1016/j.tvjl.2007.11.009

[85] P. H. Flore, "Commercialization of Veterinary Viral Vaccines,” Animal Health Research Reviews, Vol. 5, No. 2, 2004, pp. 239-242. doi:10.1079/AHR200475

[86] A. K. Shen, “The U.S. Vaccine and Immunization Enterprise: Working to Sustain and Foster Vaccine Innovation," Human Vaccines, Vol. 5, No. 10, 2009, pp. 649653. doi:10.4161/hv.5.10.9215

[87] D. A. Brake, M. McIlhaney, T. Miller, K. Christianson, A. Keene, G. Lohnas, C. Purcell, J. Neilan, C. Schutta, J. Barrera, T. Burrage, D. E. Brough and B. T. Butman, "Human Adenovirus-Vectored Foot-and-Mouth Disease Vaccines: Establishment of a Vaccine Product Profile Through in Vitro Testing," Developments in Biologicals (Basel), Vol. 134, 2012, pp. 123-133.

[88] M. J. Grubman, M. P. Moraes, C. Schutta, J. Barrera, J. Neilan, D. Ettyreddy, B. T. Butman, D. E. Brough and D. A. Brake, "Adenovirus Serotype 5-Vectored Foot-andMouth Disease Subunit Vaccines: The First Decade,” Future Virology, Vol. 5, No. 1, 2010, pp. 51-64. doi: $10.2217 /$ fvl.09.68

[89] M. Bublot, N. Pritchard, D. E. Swayne, P. Selleck, K. Karaca, D. L. Suarez, J. C. Audonnet and T. R. Mickle,
"Development and Use of Fowlpox Vectored Vaccines for Avian Influenza," Annals of the New York Academy of Sciences, Vol. 1081, No. 1, 2006, pp. 193-201. doi:10.1196/annals.1373.023

[90] J. Coon, M. Johnston, J. Minke, R. Pruett, S. Thompson and D. Carithers, "Analysis of Recombinant Canarypox Vectored West Nile Virus Vaccine Stability Post-Reconstitution," International Journal of Applied Research in Veterinary Medicine, Vol. 4, No. 2, 2006, pp. 115-120.

[91] H. Poulet, S. Brunet, C. Boularand, A. L. Guiot, V. Leroy, J. Tartaglia, J. Minke, J. C. Audonnet and P. Desmettre, "Efficacy of a Canarypox Virus-Vectored Vaccine Against Feline Leukaemia,” Veterinary Record, Vol. 153, No. 5, 2003, pp. 141-145. doi:10.1136/vr.153.5.141

[92] United States Department of Agriculture, "Veterinary Biological Products-Licensees and Permittees,” 2011.

[93] J. Esparza, "Progress in the Development of an Adenovirus 26 Vector Platform for HIV Vaccines," Expert Reviews in Vaccines, Vol. 12, No. 5, 2013, pp. 477-480. doi:10.1586/erv.13.26

[94] Z. C. Hartman, D. M. Appledorn and A. Amalfitano, "Adenovirus Vector Induced Innate Immune Responses: Impact upon Efficacy and Toxicity in Gene Therapy and Vaccine applications,” Virus Research, Vol. 132, No. 1-2, 2008, pp. 1-14. doi:10.1016/j.virusres.2007.10.005

[95] L. S. Wyatt, P. L. Earl, W. Xiao, J. L. Americo, C. A. Cotter, J. Vogt and B. Moss, "Elucidating and Minimizing the Loss by Recombinant Vaccinia Virus of Human Immunodeficiency Virus Gene Expression Resulting from Spontaneous Mutations and Positive Selection," Journal of Virology, Vol. 83, No. 14, 2009, pp. 7176-7184.

\section{List of Abbreviations}

AdV- adenovirus, HAdV- human adenovirus, MVA- modified vaccinia Ankara,
SIV- Swine influenza virus, PAV- porcine adenovirus, CDV- canine distemper virus. 